\title{
Static Analysis of a Fiber Reinforced Composite Beam Resting on Winkler-Pasternak Foundation
}

\author{
Şeref Doğuşcan Akbaş \\ Bursa Technical University, Department of Civil Engineering, Bursa, Turkey. \\ E-mail address: $\underline{\text { serefda@yahoo.com }}$ \\ ORCID numbers of author: \\ 0000-0001-5327-3406
}

Received date: 05.09.2020

Accepted date: 18.11 .2020

\begin{abstract}
This paper presents static analysis of a simply supported beam made of fiber reinforced composite material resting on elastic foundation. The foundation type is considered as Winkler-Pasternak foundation type. The first-shear beam theory is used in the kinematics of the beam and the Ritz method is used and in the solution of the problem. In the Ritz method, algebraic polynomials are used with the trivial functions. In the numerical examples, the effects of fibre orientation angles, the volume fraction and foundation parameters on the static deflections of fiber reinforced composite beam are investigated. The numerical results show that fiber orientation angle, volume fraction and foundation parameter have great influence on static behavior of fiber reinforced composites.
\end{abstract}

Keywords: Fiber Reinforced Composite Material; Static Analysis; Winkler-Pasternak Foundation; Ritz Method

\section{Introduction}

Fiber reinforced composite (FRC) structures are used in a lot of engineering applications, for example, airplanes, machine, marine, and civil engineering projects. FRC structures mainly preferred in the engineering projects due to their higher strength-weight ratios, more lightweight and ductile properties.

In the literature, many researchers investigated the static, dynamic and stability analyses of FRC structures in last decades. Some investigations about of FRC structures are as follows; Krawczuk et al. [1] studied the vibration of cracked composite beams. Shen [2] presented postbuckling analysis of laminated plate with thermal effects resting on elastic foundation. Sayman [3] investigated elastic-plastic analysis of aluminum metal-matrix laminated plate under thermal effect. Shukla et al. [4] presented thermal postbuckling analysis of laminated plates. Emery et al. [5] analyzed thermoelastic stress analysis of laminated orthotropic plates. Shen [6] presented thermal nonlinear analysis of functionally graded nanocomposite plates reinforced by single-walled carbon nanotubes. Akgöz and Civalek [7,8,9,10] presented mechanical behavior of composite structure resting on foundation.

Kishore et al. [11] investigated nonlinear analysis of magnetostrictive layered plate by using third order shear deformation theory. Sahoo and Singh [12] analyzed static of layered composite 
plates by using the hyperbolic zigzag theory. Houmat [13] presented nonlinear vibration of laminated composite plates with curvilinear fibers. Khorshid and Farhadi [14] analyzed hydrostatic vibration analysis of a laminated composite rectangular plate partially contacting with a bounded fluid. DeValve and Pitchumani [15] investigated damping vibration analysis of rotating composite beams with embedded carbon nanotubes. Tornabene et al. [16] investigated static and vibration analysis of laminated doubly-curved shells and panels embedded in elastic foundation by using the generalized differential quadrature. Akbaş [17-22] presented free vibration of functionally graded composite beams. Yüksel and Akbaş [23] presented thermal effects of laminated plates by using the Navier method. Draiche et al. [24] presented static analysis of laminated reinforced composite plates based on first-order shear deformation theory by using the Navier method. Jena et al. [25] analysed dynamic behavior of cracked fiber reinforced composite beams. Zenkour et al. [26] investigated torsional dynamics of carbon nanotubes embedded in viscoelastic medium. Waddar et al. [27] investigated buckling and dynamic response of cenosphere reinforced epoxy composite core sandwich beam with sisal fabric/epoxy composite facings under compressive load by experimentally. Akbaş [28-43] investigated nonlinear behavior and forced vibration analysis of composite structures. Also, many researchers investigated mechanical analysis of composite structures resting on foundation [44-60].

The main purpose of this study is to investigate the effects of the fibre orientation angles, the volume fraction and foundation parameters on the static deflections of the FRC beam in detail. In solution of the problem, first shear deformation beam theory and the energy based Ritz method are used. In the numerical results, the effects of fibre orientation angles, the volume fraction and foundation parameters on the static deflections of the FRC beam are investigated.

\section{Formulations}

Figure 1 shows a simply supported FRC beam resting on Winkler-Pasternak Foundation with with spring constant $\mathrm{k}_{\mathrm{w}}$ and $\mathrm{k}_{\mathrm{p}}$, the length $\mathrm{L}$, the height $\mathrm{h}$ and width $\mathrm{b}$ under a point load (Q) at midpoint of the beam. When the Pasternak foundation spring constant $k_{p}=0$, the foundation model reduces to Winkler type.

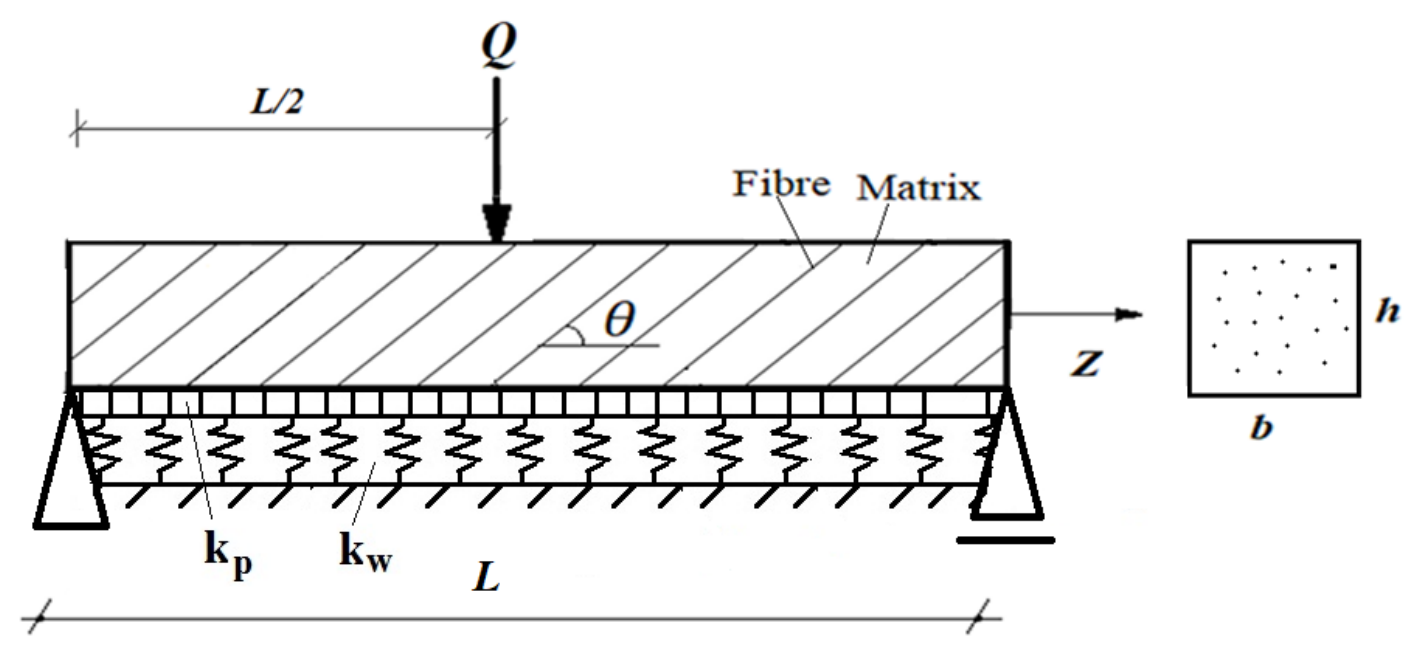

Fig.1. A simply supported FRC beam resting on Winkler-Pasternak Foundation under a point load.

The axial strain $\left(\varepsilon_{\mathrm{z}}\right)$ and shear strain $\left(\gamma_{\mathrm{zy}}\right)$ are given according to the first shear deformation 


$$
\begin{gathered}
\varepsilon_{z}=\frac{\partial u}{\partial z}-Y \frac{\partial \emptyset}{\partial z} \\
\gamma_{z y}=\frac{\partial v}{\partial z}-\emptyset
\end{gathered}
$$

where, $u, v$ and $\emptyset$ are axial displacement, vertical displacement and rotation, respectively. The constitute relation is presented as follows;

$$
\left\{\begin{array}{c}
\sigma_{z} \\
\sigma_{z y}
\end{array}\right\}=\left[\begin{array}{ll}
\bar{Q}_{11} & \bar{Q}_{16} \\
\bar{Q}_{16} & \bar{Q}_{66}
\end{array}\right]\left\{\begin{array}{c}
\epsilon_{z} \\
\gamma_{z y}
\end{array}\right\}
$$

where $\bar{Q}_{\mathrm{ij}}$ are the transformed components of the reduced constitutive tensor. The transformed components of the reduced constitutive tensor for orthotropic material are as follows:

$$
\begin{aligned}
& \bar{Q}_{11}=Q_{11} l^{4}+2\left(Q_{12}+2 Q_{66}\right) l^{2} n^{2}+Q_{22} n^{4} \\
& \bar{Q}_{12}=\left(Q_{11}+Q_{22}-4 Q_{66}\right) \sin ^{2} \cos ^{2}+Q_{12}\left(l^{4}+n^{4}\right) \\
& \bar{Q}_{16}=\left(Q_{11}-Q_{12}-2 Q_{66}\right) n l^{3}+\left(Q_{12}-Q_{22}+2 Q_{66}\right) n^{3} l \\
& \bar{Q}_{22}=Q_{11} n^{4}+2\left(Q_{12}+2 Q_{66}\right) n^{2} l^{2}+Q_{22} l^{4} \\
& \bar{Q}_{26}=\left(Q_{11}-Q_{12}-2 Q_{66}\right) n^{3} l+\left(Q_{12}-Q_{22}+2 Q_{66}\right) n l^{3} \\
& \bar{Q}_{66}=\left(Q_{11}+Q_{22}-2 Q_{12}-2 Q_{66}\right) n^{2} l^{2}+Q_{66}\left(n^{4}+l^{4}\right)
\end{aligned}
$$

where $l=\cos \theta$ and $n=\sin \theta, \theta$ indicates the fiber orientation angle and the expressions of $Q_{\mathrm{ij}}$ are as follows;

$$
\begin{aligned}
Q_{11} & =\frac{E_{1}}{1-v_{12} v_{21}}, \quad Q_{22}=\frac{E_{2}}{1-v_{12} v_{21}} \\
Q_{12} & =\frac{v_{12} E_{2}}{1-v_{12} v_{21}}=\frac{v_{21} E_{1}}{1-v_{12} v_{21}} \\
Q_{21} & =\frac{v_{12} E_{2}}{1-v_{12} v_{21}}=\frac{v_{21} E_{1}}{1-v_{12} v_{21}} \\
Q_{66} & =G_{12}
\end{aligned}
$$

where $E_{1}$ is the Young's modulus in the $X$ direction, $E_{2}$ is the Young's modulus in the $Y$ direction, $v_{12}$ and $v_{21}$ are Poisson's ratios and $G_{12}$ is the shear modulus in $X Y$ plane. The gross mechanical properties of the composite materials are calculated by using the following expression (Vinson and Sierakowski [61]):

$$
\begin{gathered}
E_{1}=E_{f} V_{f}+E_{m}\left(1-V_{f}\right), \\
E_{2}=E_{m}\left[\frac{E_{f}+E_{m}+\left(E_{f}-E_{m}\right) V_{f}}{E_{f}+E_{m}-\left(E_{f}-E_{m}\right) V_{f}}\right] \\
v_{12}=v_{f} V_{f}+v_{m}\left(1-V_{f}\right), \\
G_{12}=G_{m}\left[\frac{G_{f}+G_{m}+\left(G_{f}-G_{m}\right) V_{f}}{G_{f}+G_{m}-\left(G_{f}-G_{m}\right) V_{f}}\right] \\
\rho=\rho_{f} V_{f}+\rho_{m}\left(1-V_{f}\right),
\end{gathered}
$$

where $f$ indicates the fibre and $m$ indicates the matrix. $V_{f}$ is the volume fraction of fiber. $E$, $G, v$ and $\rho$ are the Young's modulus, the shear modulus, Poisson's ratio and mass density, respectively. 
The strain energy $\left(U_{\mathrm{i}}\right)$, and potential energy of the external loads $\left(U_{\mathrm{e}}\right)$ are presented as follows;

$$
\begin{gathered}
U_{i}=\frac{1}{2} \int_{0}^{L}\left[A_{0}\left(\frac{\partial u_{0}}{\partial z}\right)^{2}-2 A_{1} \frac{\partial u_{0}}{\partial z} \frac{\partial \emptyset}{\partial z}+A_{2}\left(\frac{\partial \emptyset}{\partial z}\right)^{2}\right] d Z+\frac{1}{2} \int_{0}^{L} K_{s} B_{0}\left[\left(\frac{\partial v_{0}}{\partial z}\right)^{2}-2 \frac{\partial v_{0}}{\partial z} \emptyset+\emptyset^{2}\right] d Z+ \\
\frac{1}{2} \int_{0}^{L}\left(k_{w}\left(v_{0}\right)^{2}+k_{p}\left(\frac{\partial v_{0}}{\partial z}\right)^{2}\right) d Z \\
U_{e}=-Q(t) v\left(z_{p}, t\right)
\end{gathered}
$$

where,

$$
\left(A_{0}, A_{1}, A_{2}\right)=\int_{A} \bar{Q}_{11}\left(1, Y, Y^{2}\right) d A, B_{0}=\int_{A} \bar{Q}_{66} d A
$$

The total potential energy of the problem is expressed as follows:

$$
\Pi=\left(U_{i}-U_{e}\right)
$$

In the solution of the problem in Ritz method, approximate solution is given as series of $i$ terms of the following form:

$$
\begin{aligned}
& u(z)=\sum_{i=1}^{\infty} \mathrm{a}_{i} \alpha_{i}(z) \\
& v(z)=\sum_{i=1}^{\infty} \mathrm{b}_{i} \beta_{i}(z) \\
& \emptyset(z)=\sum_{i=1}^{\infty} \mathrm{c}_{i} \gamma_{i}(z)
\end{aligned}
$$

where $\mathrm{a}_{\mathrm{i}}, \mathrm{b}_{\mathrm{i}}$ and $\mathrm{c}_{\mathrm{i}}$ are the unknown coefficients, $\alpha_{i}(z), \beta_{i}(z), \gamma_{i}(z)$ are the coordinate functions depend on the boundary conditions over the interval $[0, L]$. The coordinate functions for the simply supported beam are given as algebraic polynomials:

According to the minimum total potential energy principle, unknown coefficients $a_{i}, b_{i}, c_{i}$ which correspond to the minimum of the total potential energy ( $\Pi)$ are determined by the conditions:

$$
\frac{\partial \Pi}{\partial a_{i}}=0, \frac{\partial \Pi}{\partial b_{i}}=0, \frac{\partial \Pi}{\partial c_{i}}=0
$$

Differentiation of $\Pi$ in respect to unknown coefficients produces the following equilibrium equations:

$$
[\mathrm{K}]\{\mathrm{q}\}=\{\mathrm{F}\}
$$

where $[K]$ and $\{\mathrm{F}\}$ are the stiffness matrix and load vector, respectively. The detail of these expressions are given as follows;

$$
[K]=\left[\begin{array}{lll}
K_{11} & K_{12} & K_{13} \\
K_{21} & K_{22} & K_{23} \\
K_{31} & K_{32} & K_{33}
\end{array}\right]
$$

Where 


$$
\begin{gathered}
K_{i j}^{11}=\sum_{i=1}^{n} \sum_{j=1}^{n} \int_{0}^{L} A_{0} \frac{\partial \alpha_{i}}{\partial z} \frac{\partial \alpha_{j}}{\partial z} d z, K_{i j}^{12}=0, \\
K_{i j}^{13}=-\sum_{i=1}^{n} \sum_{j=1}^{n} \int_{0}^{L} A_{1} \frac{\partial \alpha_{i}}{\partial z} \frac{\partial \gamma_{j}}{\partial z} d z, K_{i j}^{21}=0, \\
K_{i j}^{22}=\sum_{i=1}^{n} \sum_{j=1}^{n} \int_{0}^{L} K_{s} B_{0} \frac{\partial \beta_{i}}{\partial z} \frac{\partial \beta_{j}}{\partial z}+\beta_{i} \beta_{j} k_{w}+\frac{\partial \beta_{i}}{\partial z} \frac{\partial \beta_{j}}{\partial z} k_{p} d z, \\
K_{i j}^{23}=-\sum_{i=1}^{n} \sum_{j=1}^{n} \int_{0}^{L} K_{s} B_{0} \frac{\partial \beta_{i}}{\partial z} \gamma_{j} d z, \\
K_{i j}^{31}=-\sum_{i=1}^{n} \sum_{j=1}^{n} \int_{0}^{L} A_{1} \frac{\partial \gamma_{i}}{\partial z} \frac{\partial \alpha_{j}}{\partial z} d z, \\
K_{i j}^{32}=-\sum_{i=1}^{n} \sum_{j=1}^{n} \int_{0}^{L} K_{s} B_{0} \gamma_{i} \frac{\partial \beta_{j}}{\partial z} d z, \\
K_{i j}^{33}=\sum_{i=1}^{n} \sum_{j=1}^{n} \int_{0}^{L} A_{2} \frac{\partial \gamma_{i}}{\partial z} \frac{\partial \gamma_{j}}{\partial z}+\sum_{i=1}^{n} \sum_{j=1}^{n} \int_{0}^{L} K_{S} B_{0} \gamma_{i} \gamma_{j} d z, \\
\{\mathrm{~F}(\mathrm{t})\}=Q \beta_{j}
\end{gathered}
$$

The dimensionless quantities can be expressed as

$$
\bar{k}_{w}=\frac{k_{w} L^{4}}{E_{f} I}, \quad \bar{k}_{p}=\frac{k_{p} L^{2}}{E_{f} I}, \overline{\mathrm{v}}=\frac{\mathrm{v}}{L}
$$

$\bar{k}_{w}$ and $\bar{k}_{p}$ are the dimensionless Winkler Pasternak parameters, $\overline{\mathrm{v}}$ is lateral dimensionless displacement.

\section{Numerical Results}

In the numerical study, static displacements of the FRC simply supported beam are presented and discussed. In the numerical examples, the materials of the beams are selected as made of graphite fibre-reinforced polyamide composite and its material parameters are as follows (Krawczuk et al [1]); $\mathrm{E}_{\mathrm{m}}=2.756 \mathrm{GPa}, \mathrm{E}_{\mathrm{f}}=275.6 \mathrm{GPa}, \mathrm{Gm}=1.036 \mathrm{GPa}, \mathrm{G}_{\mathrm{f}}=114.8 \mathrm{GPa}, v_{\mathrm{m}}=$ $0.33, v \mathrm{f}=0.2$. The geometry properties of the beam are selected as $b=0.1 \mathrm{~m}, \mathrm{~h}=0.1 \mathrm{~m}$ and $\mathrm{L}=1.2 \mathrm{~m}$. In the numerical results, number of the series term is taken as 10 . The load value is selected as $\mathrm{Q}_{0}=1000 \mathrm{kN}$.

In figure 2, effects of the volume fraction of fiber $\left(\mathrm{v}_{\mathrm{f}}\right)$ on the lateral static dimensionless displacements of FRC beam at midpoint $\left(\overline{\mathrm{v}}_{m}\right)$ are presented with effects of foundation parameter for $\theta=30$. It is seen from figure 2 that, displacements of the FRC beam decrease with increasing of the volume fraction of fiber and foundation stiffness parameters due to the bending rigidity increases according to Eq. 5. With increasing of foundation stiffness parameters, the difference among the results of $v_{f}$ decreases considerably. It is seen from figures 2 that Pasternak parameter $\bar{k}_{p}$ is more effective than Winkler parameter $\bar{k}_{w}$ on the behavior of the volume fraction of fiber.

In figure 3 , effects of the fiber orientation angles $(\theta)$ on the lateral static dimensionless displacements of FRC beam at midpoint $\left(\overline{\mathrm{v}}_{m}\right)$ are presented with effects of foundation parameter for $\mathrm{v}_{\mathrm{f}}=0.3$. Figure 3 shows that, displacements of the FRC beam increase with increasing of the fiber orientation angles $(\theta)$ due to the bending rigidity increases according to 
Eq. 3. It is observed from figure 3, Pasternak parameter $\bar{k}_{p}$ is more effective on the results of fiber orientation angles like the results of the volume fraction of fiber.
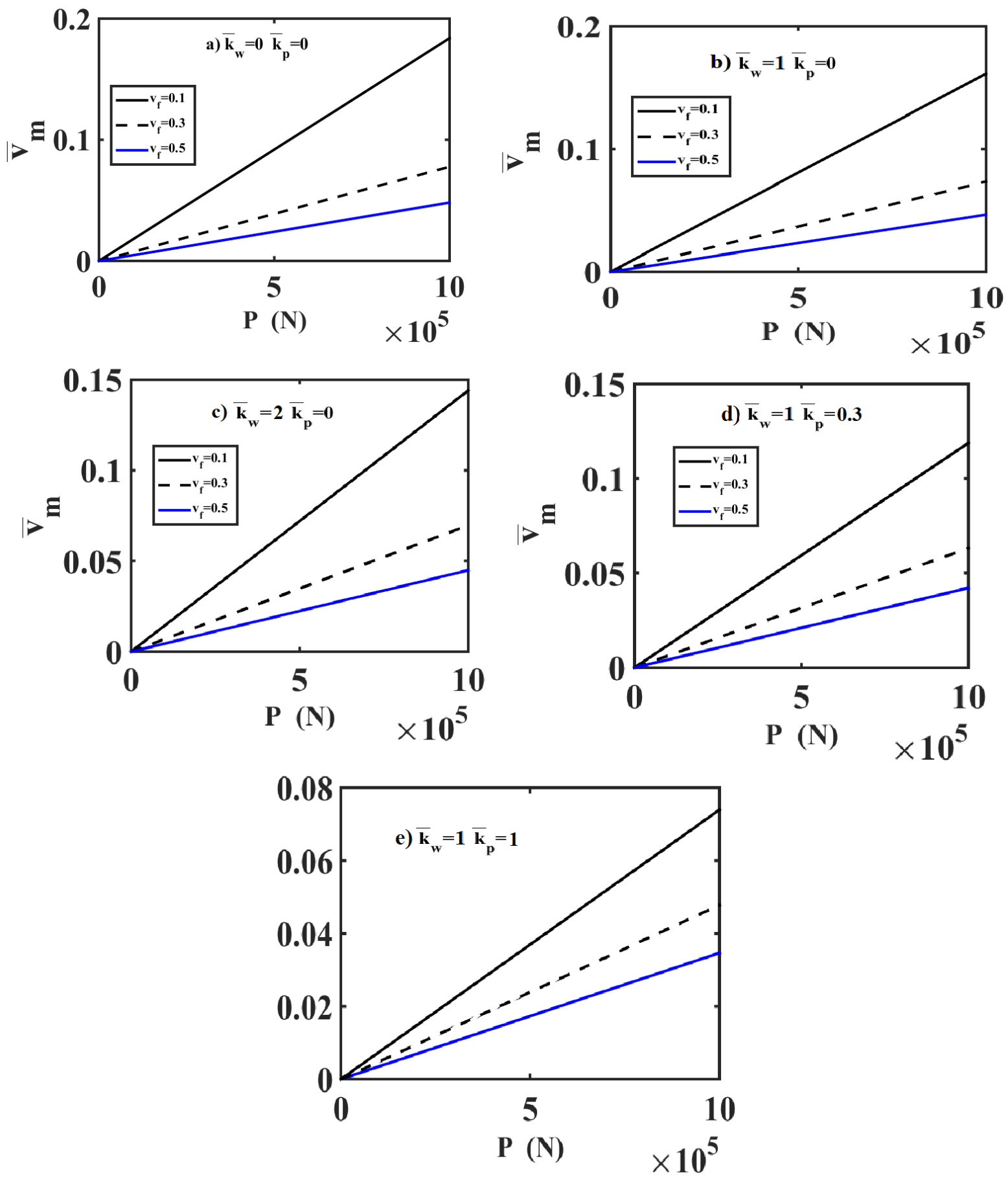

Fig.2. Load - dimensionless lateral displacement (at midpoint) relation for different values of the volume fraction of fiber $\left(\mathrm{v}_{\mathrm{f}}\right)$ for a) $\left.\bar{k}_{w}=0, \bar{k}_{p}=0 \mathrm{~b}\right) \bar{k}_{w}=1, \bar{k}_{p}=0$, c) $\bar{k}_{w}=2, \bar{k}_{p}=0$, d) $\bar{k}_{w}=$ $1, \bar{k}_{p}=0.3$, e) $\bar{k}_{w}=1, \bar{k}_{p}=1$ 

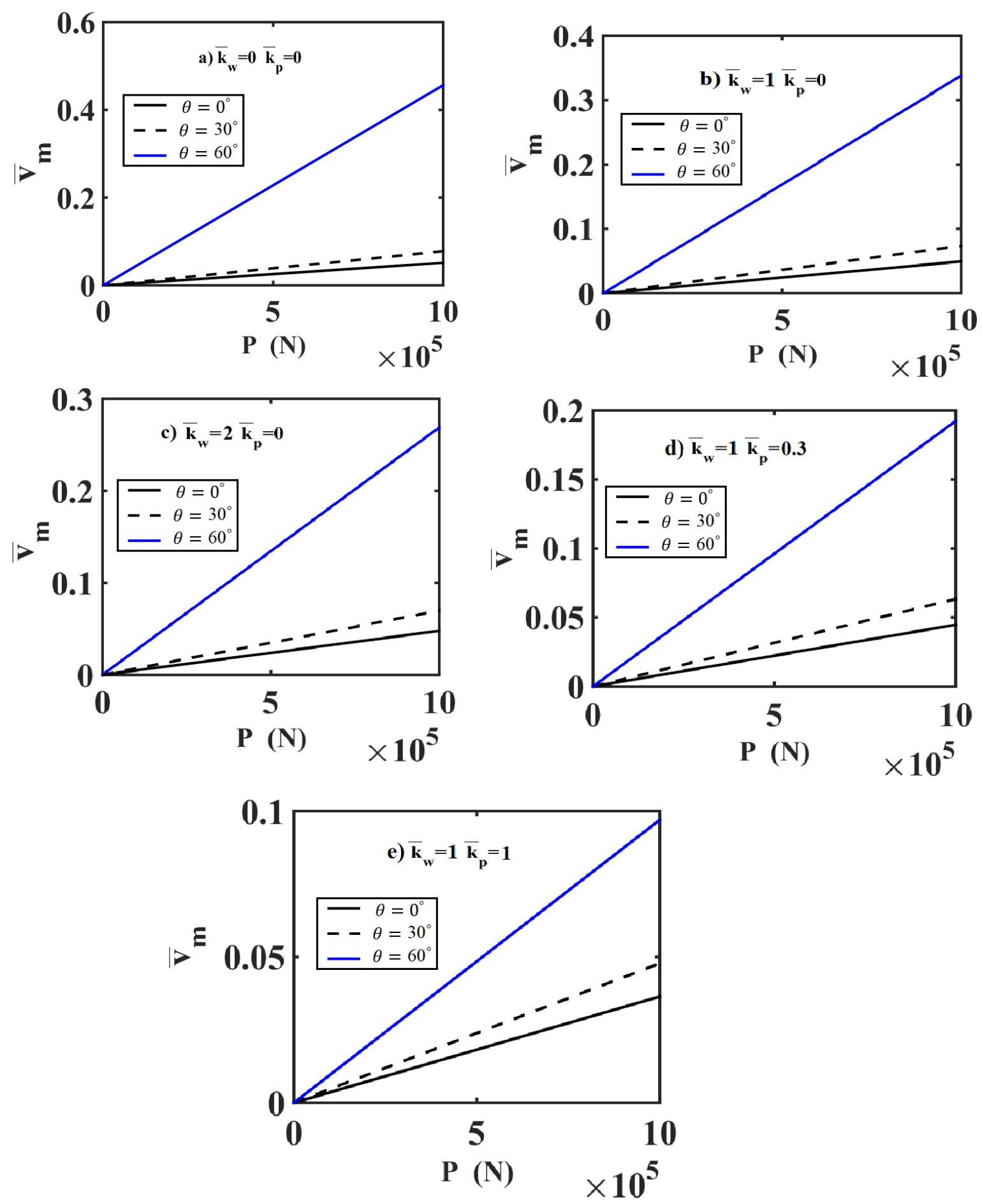

Fig.3. Load - dimensionless lateral displacement (at midpoint) relation for different values of the fiber orientation angles $(\theta)$ for a) $\bar{k}_{w}=0, \bar{k}_{p}=0$ b) $\bar{k}_{w}=1, \bar{k}_{p}=0$, c) $\bar{k}_{w}=2, \bar{k}_{p}=0$, d) $\bar{k}_{w}=1$

$$
\text { , } \bar{k}_{p}=0.3, \text { e) } \bar{k}_{w}=1, \bar{k}_{p}=1
$$

\section{Conclusions}

Effects of Winkler-Pasternak foundation parameters and composite material parameters on the static displacements of the FRC simply supported beam are investigated in this paper by using the first shear deformation beam theory. In solution of the problem, the energy based Ritz 
method is implemented. The presented results show that the displacements of FRC beam change significantly with fiber orientation angle and the volume fraction. The Pasternak parameter is a great influence on behavior of material properties of FRC.

\section{References}

[1] Krawczuk, M., Ostachowicz W., Zak, A., Modal analysis of cracked, unidirectional composite beam, Composites Part B: Engineering, 28(5-6), 641-650, 1997.

[2] Shen, H.S., Thermal postbuckling behavior of imperfect shear deformable laminated plates with temperature-dependent properties. Computer Methods in Applied Mechanics and Engineering, 190(40-41), 5377-5390, 2001.

[3] Sayman, O., Elastic-plastic and residual stresses in symmetric aluminum metal-matrix laminated plates under a linear thermal loading. Journal of Thermal Stresses, 26(4), 391406, 2003.

[4] Shukla, K.K., Huang, J.H., Nath, Y., Thermal postbuckling of laminated composite plates with temperature dependent properties. Journal of Engineering Mechanics, 130(7), 818$825,2004$.

[5] Emery, T.R., Dulieu-Barton, J.M., Earl, J.S., Cunningham, P.R. A generalised approach to the calibration of orthotropic materials for thermoelastic stress analysis. Composites Science and Technology, 68(3-4), 743-752, 2008.

[6] Shen, H.S., Nonlinear bending of functionally graded carbon nanotube-reinforced composite plates in thermal environments. Composite Structures, 91(1), 9-19, 2009.

[7] Akgoz, B., Civalek, O., Nonlinear vibration analysis of laminated plates resting on nonlinear two-parameters elastic foundations. Steel and Composite Structures, 11(5), 403-421, 2011.

[8] Akgöz, B., Civalek, Ö.,Thermo-mechanical buckling behavior of functionally graded microbeams embedded in elastic medium. International Journal of Engineering Science, 85, 90-104, 2014.

[9] Akgöz, B., Civalek, Ö., Modeling and analysis of micro-sized plates resting on elastic medium using the modified couple stress theory. Meccanica, 48(4), 863-873, 2013.

[10] Akgöz, B., Civalek, Ö., Bending analysis of embedded carbon nanotubes resting on an elastic foundation using strain gradient theory. Acta Astronautica, 119, 1-12, 2016.

[11] Kishore, M.H., Singh, B.N., Pandit, M.K., Nonlinear static analysis of smart laminated composite plate. Aerospace Science and Technology, 15(3), 224-235, 2011.

[12] Sahoo, R., Singh, B.N., A new inverse hyperbolic zigzag theory for the static analysis of laminated composite and sandwich plates. Composite structures, 105, 385-397, 2013.

[13] Houmat, A., Nonlinear free vibration of laminated composite rectangular plates with curvilinear fibers. Composite Structures, 106, 211-224, 2013.

[14] Khorshid, K., Farhadi, S., Free vibration analysis of a laminated composite rectangular plate in contact with a bounded fluid. Composite structures, 104, 176-186, 2013.

[15] DeValve, C. and Pitchumani, R. (2014), Analysis of vibration damping in a rotating composite beam with embedded carbon nanotubes, Composite Structures, 289-296, 2014.

[16] Tornabene, F., Fantuzzi, N., Viola, E. and Reddy, J.N., Winkler-Pasternak foundation effect on the static and dynamic analyses of laminated doubly-curved and degenerate shells and panels, Composites Part B: Engineering, 57, 269-296, 2014.

[17] Akbaş, Ş.D., Static analysis of a functionally graded beam with edge cracks on elastic foundation. In Proceedings of the 9 th International Fracture Conference, Istanbul, Turkey (pp. 70-80), 2011. 
[18] Akbaş, Ş.D., Free vibration characteristics of edge cracked functionally graded beams by using finite element method. International Journal of Engineering Trends and Technology, 4(10), 4590-4597, 2013.

[19] Akbaş, Ş.D., Free vibration of axially functionally graded beams in thermal environment. International Journal of Engineering \& Applied Sciences, 6(3), 37-51, 2014.

[20] Akbaş, Ş.D., Free vibration and bending of functionally graded beams resting on elastic foundation. Research on Engineering Structures and Materials, 1(1), 2015.

[21] Akbaş, Ş.D., Free Vibration Analysis of Edge Cracked Functionally Graded Beams Resting on Winkler-Pasternak Foundation. International Journal of Engineering \& Applied Sciences, 7(3), 1-15, 2015.

[22] Akbaş, Ş.D., Fonksiyonel derecelendirilmiş ortotropik bir kirişin statik ve titreşim davranışlarının incelenmesi. Balıkesir Üniversitesi Fen Bilimleri Enstitüsü Dergisi, 20(1), 69-82, 2018.

[23] Yüksel, Y. Z., Akbaş, Ş. D. (2018). Free vibration analysis of a cross-ply laminated plate in thermal environment. International Journal of Engineering and Applied Sciences, 10(3), 176-189, 2018.

[24] Draiche, K., Bousahla, A.A., Tounsi, A., Alwabli, A. S., Tounsi, A. and Mahmoud, S.R. (2019), "Static analysis of laminated reinforced composite plates using a simple first-order shear deformation theory", Computers and Concrete 24(4), 369-378.

[25] Jena, P.C. Parhi, D.R. and Pohit, G. (2016), "Dynamic Study of Composite Cracked Beam by Changing the Angle of Bidirectional Fibres", Iranian Journal of Science and Technology, Transactions A: Science 40(1), 27-37.

[26] Zenkour, A. M. (2016), "Torsional Dynamic Response of a Carbon Nanotube Embedded in Visco-Pasternak's Medium”, Mathematical Modelling and Analysis, 21(6), 852-868.

[27] Waddar, S., Pitchaimani, J., Doddamani, M., \& Barbero, E. (2019), "Buckling and vibration behaviour of syntactic foam core sandwich beam with natural fiber composite facings under axial compressive loads", Composites Part B: Engineering, 175, 107133.

[28] Akbaş, Ş.D., Post-buckling analysis of axially functionally graded three-dimensional beams. International Journal of Applied Mechanics, 7(03), 1550047, 2015.

[29] Akbaş, Ş.D., Nonlinear static analysis of functionally graded porous beams under thermal effect. Coupled Syst. Mech, 6(4), 399-415, 2017.

[30] Akbaş, Ş.D., Geometrically nonlinear analysis of functionally graded porous beams. Wind and Structures, 27(1), 59-70, 2018.

[31] Akbaş, Ş.D., Geometrically nonlinear analysis of a laminated composite beam. Structural Engineering and Mechanics, 66(1), 27-36, 2018.

[32] Akbaş, Ş.D., Stability of a non-homogenous porous plate by using generalized differantial quadrature method. International Journal of Engineering and Applied Sciences, 9(2), 147$155,2017$.

[33] Akbaş, Ş.D., Static analysis of a nano plate by using generalized differential quadrature method. International Journal of Engineering and Applied Sciences, 8(2), 30-39, 2016.

[34] Akbaş, Ş.D., Wave propagation analysis of edge cracked beams resting on elastic foundation. International Journal of Engineering and Applied Sciences, 6(1), 40-52, 2014.

[35] Akbaş, Ş.D., Investigation on free and forced vibration of a bi-material composite beam. Journal of Polytechnic-Politeknik Dergisi, 21(1), 65-73, 2018.

[36] Akbaş, Ş.D. Wave propagation of a functionally graded beam in thermal environments. Steel and Composite Structures, 19(6), 1421-1447, 2015.

[37] Akbaş, Ş.D.. (2017). Free vibration of edge cracked functionally graded microscale beams based on the modified couple stress theory. International Journal of Structural Stability and Dynamics, 17(03), 1750033, 2017. 
[38] Akbaş, Ş.D., Vibration and static analysis of functionally graded porous plates. Journal of Applied and Computational Mechanics, 3(3), 199-207, 2017.

[39] Akbaş, Ş.D., Thermal post-buckling analysis of a laminated composite beam. Structural Engineering and Mechanics, 67(4), 337-346, 2018.

[40] Akbaş, Ş.D., Geometrically nonlinear analysis of a laminated composite beam. Structural Engineering and Mechanics, 66(1), 27-36, 2018.

[41] Akbaş, Ş.D., Geometrically nonlinear analysis of functionally graded porous beams. Wind and Structures, 27(1), 59-70, 2018.

[42] Akbaş, Ş.D., Hygrothermal post-buckling analysis of laminated composite beams. International Journal of Applied Mechanics, 11(01), 1950009, 2019.

[43] Akbaş, Ş.D., Large deflection analysis of a fiber reinforced composite beam. Steel and Composite Structures, 27(5), 567-576, 2018.

[44] Alsaid-Alwan H.H.S and Avcar, M., Analytical solution of free vibration of FG beam utilizing different types of beam theories: A comparative study, Computers and Concrete, 26(3), 285-292, 2020.

[45] Arefi, M., \& Civalek, Ö.,Static analysis of functionally graded composite shells on elastic foundations with nonlocal elasticity theory. Archives of Civil and Mechanical Engineering, 20(1), 1-17, 2020.

[46] Avcar, M., Free vibration of non-homogeneous beam subjected to axial force resting on Pasternak foundation, J. Polytechnic, 19(4), 507-512, 2016.

[47] Avcar, M., Effects of material non-homogeneity and two parameter elastic foundation on fundamental frequency parameters of Timoshenko beams, Acta Physica Polonica A, 130(1), 375-378, 2016.

[48] Avcar, M. and Mohammed, W.K.M., Free vibration of functionally graded beams resting on Winkler-Pasternak foundation. Arabian Journal of Geosciences, 11(10), 232, 2018.

[49] Bisheh, H. and Civalek, Ö., Vibration of smart laminated carbon nanotube-reinforced composite cylindrical panels on elastic foundations in hygrothermal environments. ThinWalled Structures, 155, 106945, 2020.

[50] Bousahla, A.A., Bourada, F., Mahmoud, S.R., Tounsi, A., Algarni, A., Adda Bedia, E.A., Tounsi, A., Buckling and dynamic behavior of the simply supported CNT-RC beams using an integral-first shear deformation theory, Computers and Concrete, 25(2), 155-166, 2020.

[51] Bourada, F., Bousahla, A.A., Tounsi, A., Adda Bedia, E.A., Mahmoud, S.R., Benrahou, K.H., Tounsi, A., "Stability and dynamic analyses of SW-CNT reinforced concrete beam resting on elastic-foundation", Computers and Concrete, 25(6), 485-495, 2020.

[52] Civalek, Ö., Avcar, M., Free vibration and buckling analyses of CNT reinforced laminated non-rectangular plates by discrete singular convolution method. Engineering with Computers. https://doi.org/10.1007/s00366-020-01168-8, 2020.

[53] Civalek Ö, Acar MH. Discrete singular convolution method for the analysis of Mindlin plates on elastic foundations. Int J Press Vessel Pip , 84 (9):527-535, 2007.

[54] Akgöz, B., Civalek, Ö., A size-dependent beam model for stability of axially loaded carbon nanotubes surrounded by Pasternak elastic foundation, Composite Structures, 176, 10281038, 2017.

[55] Civalek, Ö., Geometrically non-linear static and dynamic analysis of plates and shells resting on elastic foundation by the method of polynomial differential quadrature (PDQ), Firat University (in Turkish), Elazığ, Furat University, 2004.

[56] Civalek, Ö., Kiracioglu, O., Free vibration analysis of Timoshenko beams by DSC method, International Journal for Numerical Methods in Biomedical Engineering, 26(12), 18901898, 2010. 
[57] Civalek, Ö., Yavas, A., Large deflection static analysis of rectangular plates on two parameter elastic foundations, International Journal of Science and Technology, 1(1), 43$50,2006$.

[58] Mercan, K., Demir, Ç., Civalek, Ö., Vibration analysis of FG cylindrical shells with powerlaw index using discrete singular convolution technique, Curved and Layered Structures, 3(1), 82-90, 2016.

[59] Civalek, Ö., Geometrically nonlinear dynamic and static analysis of shallow spherical shell resting on two-parameters elastic foundations, International Journal of Pressure Vessels and Piping, 113, 1-9, 2014.

[60] Civalek, Ö., Finite Element analysis of plates and shells. Elazığg, Firat University (in Turkish), 1998.

[61] Vinson, J.R. and Sierakowski, R.L., Behaviour of structures composed of composite materials, Kluwer Academic Publishers, ISBN 978-140-2009-04-4, Netherlands, 2002. 